\title{
Computational analysis of clustering techniques for the efficient cluster head selection
}

\author{
Anil Khandelwal ${ }^{1 *}$ and Yogendra Kumar Jain ${ }^{2}$ \\ Research Scholar, Electronics \& Communication, RGPV Bhopal, MP, India ${ }^{1}$ \\ Associate Professor Department of Electronics and Instrumentation Engineering, SATI Vidisha, MP, India ${ }^{2}$
}

Received: 25-September-2019; Revised: 14-November-2019; Accepted: 19-November-2019

(C)2019 Anil Khandelwal and Yogendra Kumar Jain. This is an open access article distributed under the Creative Commons Attribution (CC BY) License, which permits unrestricted use, distribution, and reproduction in any medium, provided the original work is properly cited.

\begin{abstract}
In the current era there are lots of work have been carried out in the direction of cluster heads (CHs) selection in wireless sensor network (WSN). Despite of these works there is still need of improvement in the suggested methods and approach. This paper provides a computational analysis of the related method published of clustering techniques for the efficient cluster head selection and based on the other approaches. In general k-means, fuzzy c-means (FCM) and hierarchical clustering have been considered for the analysis along with the computational measures. This study explores the analytical and experimental discussion and the trends for the efficient cluster head selection.
\end{abstract}

\section{Keywords}

WSN, CHs, K-means, FCM, Computational analysis.

\section{Introduction}

Wireless sensor networks (WSNs) are the heterogeneous network for the communication between the nodes for the successful transmission of the data to the sink node $[1,2]$. The major drawbacks suggested in the previous works are the resource limitation and the communication failure [3-7]. The important factors for the analysis are network lifetime, energy efficiency and data synchronization $[8,9]$. The main components of WSNs are sensors, processors, memory and power sources (Figure 1).

The computational analysis scopes of this paper are as follows:

1. To discuss the aggregation of data.

2. To include the analysis of different performance computability with different parametric variations.

3. To discuss the cluster heads (CHs) selection, ranking, scaling, delay intervals, and delivery time and energy consumption.

4. Evaluation with different approaches.

5. To evaluate the utilization of $\mathrm{k}$-means and FCM in an efficient way $[10,11]$.

*Author for correspondence

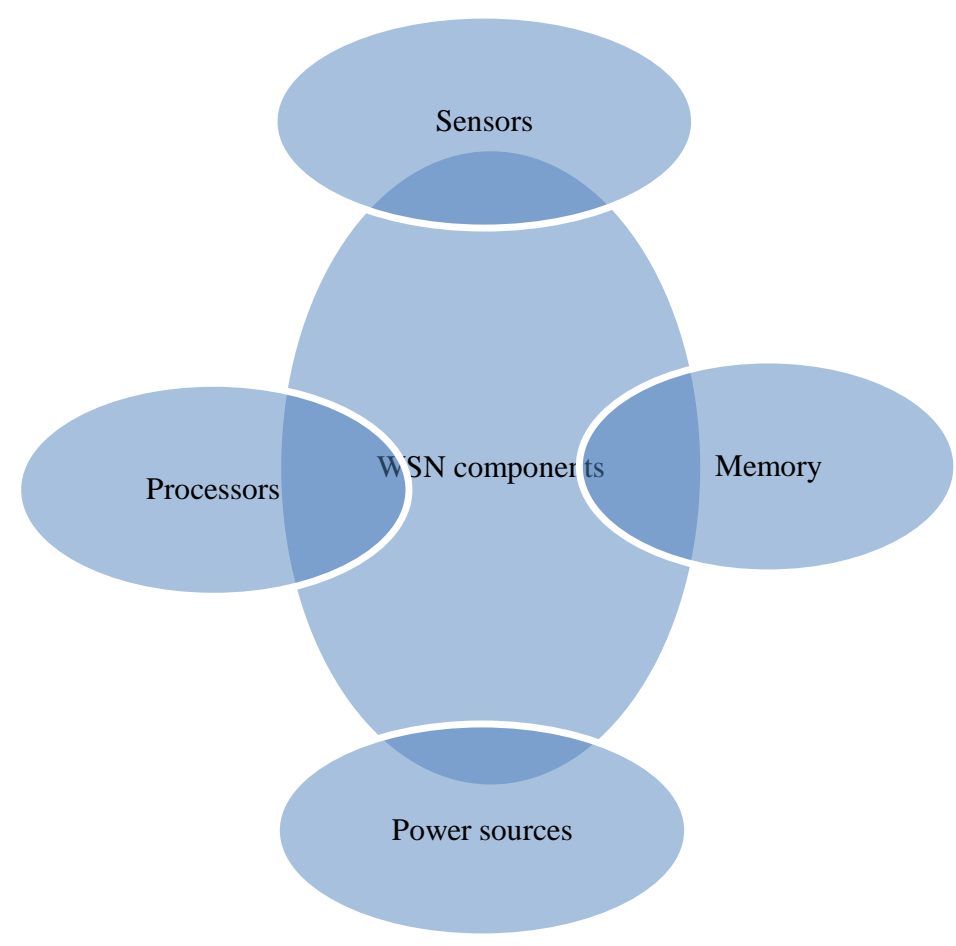

Figure 1 Main components of WSN 
The most of the WSNs applications utilized remote sensor systems applications in the field of transport dynamic directing administration and checking of frameworks, for example, observing of traffic,

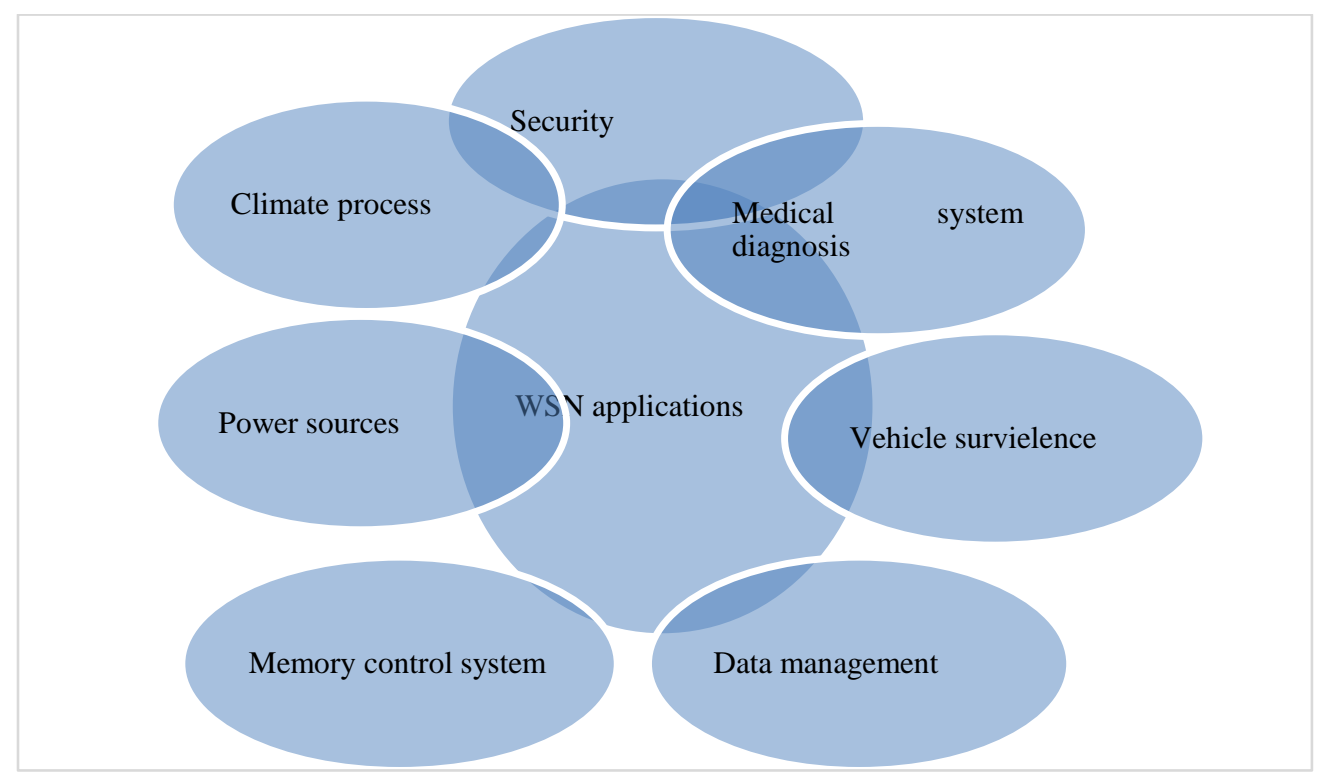

Figure 2 Application of WSN

\section{Literature review}

In 2015, Malakooti et al. [12] discussed about the WSNs capability of sensing, data processing, and storage and data transmission. They have suggested that the information clustering is an efficient way of handling these aspects. They have suggested that the automatic turn off of the unused sensor for the optimal path can decrease the redundancy in the data transmission stage. They have applied discrete wavelet transform (DWT) and singular value decomposition (SVD) for the data compression and feature extraction. They have also applied correlation algorithm for the redundancy minimization.

In 2015, Kumrawat and Dhawan [13] discuss about the security aspect in the wireless ad-hoc network. They have considered WSN for the energy optimization and network scaling. Their results show the effectiveness in terms of long network lifetime and enhanced energy optimization.

In 2015, Desai and Rana [14] discussed about the computation and communications capabilities in respect of WSN. They have suggested the battery drain problem in WSN due to the computation and communication. They have suggested clustering as the key issue for this type of problem. Their proposed method utilizes the cluster head $(\mathrm{CH})$ selection based on distance between nodes and energy of the nodes. Maximum distance and energy have been considered as the selection criteria.

In 2015, Bhat and Reddy [15] discussed about the security bottlenecks in WSN. They have suggested that the secured clustering and backup nodes may enhance the network lifetime. They have proposed a multipath node disjoint route discovery algorithm. The simulation has been performed on the NS2 platform. Their result shows that their approach improves the efficiency.

In 2015, Nguyen and Teague [16] explore the discrete cosine transform and clustering in WSN. They have discussed and analyzed communication cost in the data transmission. For experimentation they have considered noise and noiseless environment both. They have successfully recovered the data from the base station and transformed large coefficients.

In 2015, Zhou et al. [17] discuss the k-means impact of clustering in WSN. They have proposed a distributed k-means for clustering sensors based on the collaboration of the neighboring sensor nodes. 
They have used attribute-weight entropy method for the important feature extraction. They have performed experimentation on synthetic datasets.

In 2015, Tinker and Chinara [18] discussed energy conversation issue in WSN. They have pointed that clustering only is not sufficient for the energy conservation. They have utilized the sensor node capability in the power transmission range. They have suggested, by this they can minimize the network energy consumption. They have also included a s-node mechanism for the task. It is like a transmitter which can be helpful in sending the aggregated data to the sink. They have simulated their mechanism with LEACH and LEACH-C protocol. Their result shows the improvement.

In 2015, Pant et al. [19] discussed the energy saving issue in case of WSN. They have suggested clustering for the efficient energy saving. They have suggested that it is also useful in network life time and scalability. Their results show that by their approach wireless network lifetime have been increased.

In 2016, Yuvaraj and Narayana [20] suggested a hybrid cluster head selection method with the parameters Location centrality and Nodes' lingering energy on the fixed clusters. The recreation result represents that the proposed calculation is great at burden offsetting with low control overhead and stretching out system lifetime contrasted with regular steering calculation drain.

In 2016, Devi and Rao [21] discussed ground breaking technology in case of WSN. They have suggested that almost all routing protocols main aim is to maximize the lifetime. They have suggested that the existing protocols are data centric, hierarchical, and location based and on demand routing protocols. They have also suggested the cluster-based protocol like deterministic energy-efficient clustering (DEC), stable election protocol (SEP) and stable election protocol enhancement (SEP-E). In this paper they have compared the performances of SEP and DEC. Their result indicates that SEP-E have more energy available than DEC and SEP protocol.

In 2017, Abushiba et al. [22] discussed large scale integration and energy-efficiency in WSN. They have suggested that the sensor-node energy has been consumed in case of energy-efficient solutions. They have suggested that the LEACH as the most common energy-efficiency sensor network. They have proposed a CH-LEACH. They have evaluated the performances based on energy consumption and network lifetime. They have found that the $\mathrm{CH}$ LEACH provides $91 \%$ network lifetime which is better than LEACH.

In 2017, Echoukairi et al. [23] discussed WSN in terms of centralized clustering approach. It is based on k-means method. They want to improve the LEACH-C protocol by applying k-means algorithm. It may be helpful in the new cluster scheme and therefore lengthen the lifetime of the sensor network. They have implemented their approach in the NS2 simulator. The parameters for the performances they have considered are average end-to-end delay, packet delivery ratio, the average energy consumption, average throughput and control routing overhead. Their approach result shows that it can effectively reduce the overhead.

In 2019, Masoud et al. [24] discussed about the clustering impact on all the cases. They have proposed a hybrid clustering routing protocol (HCP). Their proposed protocol having cluster formation and data forwarding phases. In cluster formation and data forwarding phase, traffic has been decided to forward to the sink node according. It is based on the threshold value. If the nodes are less on the network, clustering will not be performed. Their result shows efficient reduction in network power consumption and increase impact has been achieved in case of network lifetime.

In 2019, Liu et al. [25] discussed about the prolonging lifetime in WSNs. They have proposed an energy efficient cluster formation algorithm based on GA-optimized Fuzzy Logic (CGAFL). In this system fuzzy inference system (FIS) has been applied. For fuzzy inference rule optimization, genetic algorithm (GA) has been used. Their results suggest that the CGAFL has the ability for the optimal fuzzy inference rules and also prolong the lifetime of WSNs. The results are based on the comparison from the LEACH, CFFL and FLCFP.

\section{Discussion and gap analysis}

This section shows the survey and result analysis based on the latest related work. Table 1 shows the methodological prospect along with the approach description for the result and method description and exploration. It also focuses on the approach proposed or used. 
Table 1 Related work discussion

\begin{tabular}{|c|c|c|c|c|}
\hline S.No & Reference & Method & Approach & Results achieved \\
\hline 1 & {$[26]$} & $\begin{array}{l}\text { Energy aware } \\
\text { virtual backbone } \\
\text { construction using } \\
\text { cluster heads }\end{array}$ & $\begin{array}{l}\text { They have proposed connected dominating set } \\
\text { nodes. They have suggested that it is an energy } \\
\text { efficient method. They have used a sample for the } \\
\text { comparison and simulation. }\end{array}$ & $\begin{array}{l}\text { The outcome demonstrates } \\
\text { that disintegration of } \\
\text { aggregate vitality over some } \\
\text { stretch of time is } \\
\text { considerably lower } \\
\text { contrasted with effectively } \\
\text { distributed work. }\end{array}$ \\
\hline 2 & [27] & $\begin{array}{l}\text { Bee colony inspired } \\
\text { clustering protocol }\end{array}$ & $\begin{array}{l}\text { They have introduced bee colony inspired } \\
\text { clustering protocol. It is for achieving for the } \\
\text { performance improvement in terms of efficiency } \\
\text { and stability. }\end{array}$ & $\begin{array}{l}\text { Their results shows the } \\
\text { usefulness of the proposed in } \\
\text { terms of the lifetime of the } \\
\text { wireless sensor network. }\end{array}$ \\
\hline 3 & {$[28]$} & $\begin{array}{l}\text { Energy efficient } \\
\text { clustering models }\end{array}$ & $\begin{array}{l}\text { They have compared sleep-wake energy balanced } \\
\text { distributed algorithm with LEACH, mod-LEACH } \\
\text { and PEGASIS. It is compared for homogeneous } \\
\text { sensor networks and heterogeneous sensor } \\
\text { networks. In terms of the quantity of alive hubs in } \\
\text { the system and the number of parcels sent to the } \\
\text { base station (BS) as two unique situations. }\end{array}$ & $\begin{array}{l}\text { The results show that the } \\
\text { sleep-wake energy balanced } \\
\text { distributed algorithm is more } \\
\text { robust and efficient in } \\
\text { increasing the network } \\
\text { efficiency. }\end{array}$ \\
\hline 4 & [29] & $\begin{array}{l}\text { Natural algorithm } \\
\text { based adaptive } \\
\text { architecture for } \\
\text { underwater WSN }\end{array}$ & $\begin{array}{l}\text { They have proposed an adaptive architecture. It is } \\
\text { based on the natural algorithms. The main aim is to } \\
\text { keep the nodes connected also in case if it is not } \\
\text { near to their cluster. For the additioanl power } \\
\text { requirement they have used an advanced node for } \\
\text { the dedicated cluster head. }\end{array}$ & $\begin{array}{l}\text { It is helpful in proper signal } \\
\text { attenuation. }\end{array}$ \\
\hline 5 & {$[30]$} & $\begin{array}{l}\text { Cooperative MIMO } \\
\text { transmission } \\
\text { clustering }\end{array}$ & $\begin{array}{l}\text { They have proposed a cooperative multiple input } \\
\text { multiple outputs for the efficient utilization in the } \\
\text { wireless sensor network. It is predicated based on } \\
\text { the space time trellis code (STTC). This approach is } \\
\text { then associated with the XOR based LEACH } \\
\text { protocol. For choice of group head, the last group } \\
\text { head and a self-assertive parallel vector are XORed } \\
\text { together. The proposed framework gets altered } \\
\text { execution and is contrasted and the current LEACH } \\
\text { convention as far as system life expectancy and } \\
\text { leftover vitality. }\end{array}$ & $\begin{array}{l}\text { They have analyzed bit error } \\
\text { rates for the several system } \\
\text { and detection techniques. }\end{array}$ \\
\hline 6 & {$[31]$} & $\begin{array}{l}\text { Balanced energy } \\
\text { consumption based } \\
\text { on clustering }\end{array}$ & $\begin{array}{l}\text { They have discussed and focused on multi-cluster- } \\
\text { head based clustering routing algorithm. They have } \\
\text { suggested that it can be helpful in achieving the } \\
\text { energy consumption of wireless sensor network } \\
\text { nodes. They have suggested that it can also be } \\
\text { helpful in the stability and extend the service life of } \\
\text { the network. They have suggested the use of } \\
\text { clustering can divides the WSN into multiple } \\
\text { clusters. In which there is a main cluster head node, } \\
\text { assistant cluster head node, cluster management } \\
\text { node and several ordinary nodes. The article } \\
\text { explains the vitality utilization model of the remote } \\
\text { sensor arrange, the system topological structure of } \\
\text { the multi-bunch head-based grouping directing } \\
\text { calculation what's more, the technique for } \\
\text { acknowledgment. }\end{array}$ & $\begin{array}{l}\text { Their results show that their } \\
\text { approach can achieve } \\
\text { preferable balance on energy } \\
\text { consumption of various } \\
\text { nodes in the WSN. So, it } \\
\text { shows improvement in the } \\
\text { service life and the } \\
\text { stability of the WSN. }\end{array}$ \\
\hline 7 & {$[32]$} & $\begin{array}{l}\text { Dynamic Clustering } \\
\text { Technique }\end{array}$ & $\begin{array}{l}\text { They have suggested that the energy consumption } \\
\text { is the major part in WSN. They have suggested } \\
\text { regarding the dynamic clustering. It shows the } \\
\text { group heads in a system and number of hubs in } \\
\text { different groups and it will be applicable on th } \\
\text { group. They have proposed a dynamic clustering. It } \\
\text { takes several prospect in case of cluster creation at }\end{array}$ & The reults supports the same. \\
\hline
\end{tabular}




\begin{tabular}{|c|c|c|c|c|}
\hline S.No & Reference & Method & Approach & Results achieved \\
\hline 8 & {$[33]$} & $\begin{array}{l}\text { Double cluster head } \\
\text { based WSN routing } \\
\text { algorithm }\end{array}$ & $\begin{array}{l}\text { the time of data transmission. } \\
\text { They have proposed a double cluster head-based } \\
\text { routing algorithm for the WSN. Their main aim is } \\
\text { for the premature death. It is due to the fast energy } \\
\text { consumption. Firstly, the ace group heads and the } \\
\text { part hubs of the bunch are decided dependent on the } \\
\text { LEACH calculation. Besides, the bad habit group } \\
\text { head is chosen from bunch part hubs as per vitality } \\
\text { devoured by all the part hubs to finish a procedure } \\
\text { of information transmission, gathering and } \\
\text { combination dependent on the standard of least } \\
\text { vitality utilization. Any part hub in the group } \\
\text { transmits the information to the bunch head close to } \\
\text { it. Both the ace group head and the bad habit bunch } \\
\text { head gather and incorporate the information, which } \\
\text { successfully diminishes and balances the vitality } \\
\text { utilization of hubs. }\end{array}$ & $\begin{array}{l}\text { Their results show that the } \\
\text { proposed approach is } \\
\text { efficient in the delay of the } \\
\text { death time in comparison to } \\
\text { LEACH. }\end{array}$ \\
\hline 9 & {$[34]$} & PSO and GA & It has been used for the communication correlation. & $\begin{array}{l}\text { The results supports the } \\
\text { correlation. }\end{array}$ \\
\hline 10 & {$[35]$} & $\begin{array}{l}\text { Multi-channel } \\
\text { media access } \\
\text { (Asynchronous) }\end{array}$ & $\begin{array}{l}\text { It has been used for synchronous multiple access } \\
\text { support and validation case of different channel } \\
\text { modulation. }\end{array}$ & $\begin{array}{l}\text { The results shows the } \\
\text { replication in different } \\
\text { system with multiple } \\
\text { channels. }\end{array}$ \\
\hline 11 & {$[36]$} & $\begin{array}{l}\text { Clustering for } \\
\text { Parallel PHY-Layer } \\
\text { Processing }\end{array}$ & $\begin{array}{l}\text { They have developed and establish a unified } \\
\text { theoretical framework. It is helpful in dynamic } \\
\text { clustering. They have used the C-RAN channel } \\
\text { matrices. Based on the hybridization of the above } \\
\text { approach they have proposed a nested dynamic } \\
\text { clustering approach. Their approach is useful in the } \\
\text { system scalability. }\end{array}$ & $\begin{array}{l}\text { Their results shows that the } \\
\text { computation time is reduced } \\
\text { by their approach. }\end{array}$ \\
\hline 12 & {$[37]$} & $\begin{array}{l}\text { Sequence Equalizer } \\
\text { in Direct Detection } \\
\text { DQPSK } \\
\text { Optical Signaling }\end{array}$ & $\begin{array}{l}\text { They have proposed a Sequence Equalizer based on } \\
\text { clustering. It is based on intensity modulated direct } \\
\text { detection optical communications. Their appraoch } \\
\text { is capable in channel response estimation without } \\
\text { any parameter and sequence estimation using the } \\
\text { Viterbi algorithm. }\end{array}$ & $\begin{array}{l}\text { Their simulation shows the } \\
\text { efficiency in terms of cluster } \\
\text { based sequence equalizer. }\end{array}$ \\
\hline 13 & {$[38]$} & 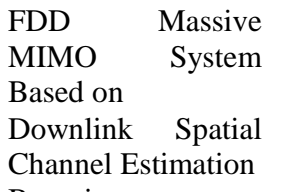 & $\begin{array}{l}\text { They have suggested that the channel state } \\
\text { information is an important aspect in the MIMO } \\
\text { networks. They have suggested an acquisition } \\
\text { scheme based on channel state information. It is } \\
\text { properly corelated with uplink and downlink. }\end{array}$ & $\begin{array}{l}\text { Their proposed approach } \\
\text { Shows the less cost overhead } \\
\text { and it is capable in finding } \\
\text { the channel statistics. }\end{array}$ \\
\hline 14 & [39] & $\begin{array}{l}\text { Bayesian } \\
\text { Estimation of } \\
\text { Cluster-Sparse } \\
\text { Channels }\end{array}$ & $\begin{array}{l}\text { They have used Bayesian estimation framework for } \\
\text { the problem of channel impulse response } \\
\text { estimation. They have developed a minimum mean } \\
\text { squared error estimator for the exploration of the } \\
\text { sparsity of the received signal profile. The } \\
\text { symmetrical groups, and the structure of the } \\
\text { estimation grid, all joined in acknowledgment of } \\
\text { the MMSE channel estimator. The MMSE } \\
\text { estimator figurings come down to less difficult in- } \\
\text { bunch counts that can be reused in various groups. } \\
\text { The decrease in computational unpredictability } \\
\text { takes into consideration with exact execution of the } \\
\text { MMSE estimator. The proposed methodology is } \\
\text { tried utilizing engineered Gaussian channels. }\end{array}$ & $\begin{array}{l}\text { Their results are better in } \\
\text { terms of Symbol-error-rate } \\
\text { and computation time. }\end{array}$ \\
\hline 15 & {$[40]$} & $\begin{array}{l}\text { Random-Cluster } \\
\text { Model }\end{array}$ & $\begin{array}{l}\text { They have investigated and analyzed the } \\
\text { intercluster parameters whichis relied on co- } \\
\text { existing cluster number, delay offset, power offset } \\
\text { and cross correlations. }\end{array}$ & $\begin{array}{l}\text { Their results shows that their } \\
\text { approach is efficient in path } \\
\text { loss model. }\end{array}$ \\
\hline
\end{tabular}




\begin{tabular}{|c|c|c|c|c|}
\hline S.No & Reference & Method & Approach & Results achieved \\
\hline 16 & {$[41]$} & $\begin{array}{l}\text { Multiuser } \\
\text { Millimeter-Wave } \\
\text { Massive MIMO- } \\
\text { OFDM Channels }\end{array}$ & $\begin{array}{l}\text { They have discussed about millimeter wave } \\
\text { (mmWave). It is discussed in terms of MIMO } \\
\text { systems. They have suggested that the efficient } \\
\text { beamforming is depends on the acurate channel } \\
\text { state information estimation. They have applied } \\
\text { nearest neighbor pattern learning algorithm for } \\
\text { improving the attainable channel estimation } \\
\text { performance. }\end{array}$ & $\begin{array}{l}\text { Their approach is capable in } \\
\text { the performance bound based } \\
\text { on the state evolution. Their } \\
\text { simulation shows that the } \\
\text { mmWave systems associated } \\
\text { with a broad bandwidth. }\end{array}$ \\
\hline 17 & {$[42]$} & $\begin{array}{l}\text { Clustering } \\
\text { Approach for } \\
\text { Detection and Time } \\
\text { of } \\
\text { Arrival Estimation }\end{array}$ & $\begin{array}{l}\text { They have discussed and analyzed the detection and } \\
\text { time-of-arrival (ToA) estimation of underwater } \\
\text { acoustic signals. These undertakings are key } \\
\text { empowering advancements for submerged acoustic } \\
\text { sensors applications counting SONAR, acoustic } \\
\text { correspondence, and profundity finders. Location } \\
\text { more often than not includes looking at the yield of } \\
\text { the coordinated channel to a location edge, and the } \\
\text { first maxima that scopes the limit is viewed as the } \\
\text { ToA. The recognition edge is set by the normal } \\
\text { conveyance of the commotion and the objective } \\
\text { false alert furthermore, location probabilities. Be } \\
\text { that as it may, due to the solid multipath } \\
\text { furthermore, the nearness of transient commotion in } \\
\text { the submerged acoustic channel, target execution is } \\
\text { difficult to ensure. }\end{array}$ & $\begin{array}{l}\text { Their approach is found to be } \\
\text { successful in case of sea } \\
\text { experiment testing. Proposed } \\
\text { method was successfully } \\
\text { tested in a sea experiment } \\
\text { conducted in the } \\
\text { Mediterranean Sea at water } \\
\text { depth of } 900 \mathrm{~m} \text {. }\end{array}$ \\
\hline 18 & [43] & $\begin{array}{l}\text { Multipath } \\
\text { Components } \\
\text { Clustering } \\
\text { Algorithm }\end{array}$ & $\begin{array}{l}\text { They have suggested that effective clustering } \\
\text { algorithm for the wireless channels or time-variant } \\
\text { channels is a major research problem. They have } \\
\text { proposed a tracking algorithm which is based on the } \\
\text { probability maximization estimation and the } \\
\text { KPowerMeans. }\end{array}$ & $\begin{array}{l}\text { Their results have been } \\
\text { validated based on dynamic } \\
\text { channels and shows } \\
\text { improved results. }\end{array}$ \\
\hline 19 & [44] & $\begin{array}{l}\text { Common Sparsity } \\
\text { and Cluster } \\
\text { Structure based } \\
\text { Channel Estimation }\end{array}$ & $\begin{array}{l}\text { They have proposed a new channel estimation } \\
\text { scheme for downlink channels in MIMO systems. } \\
\text { To assess the downlink } \\
\text { directs in the multi-subcarrier situation, the basic } \\
\text { sparsity what's more, bunch structure is misused, } \\
\text { which is obscure to the client. It is discussed based } \\
\text { on the local beta process (LBP). The framework } \\
\text { used is Bayseian framework. Then they have } \\
\text { proposed a common structure based multi- } \\
\text { subcarrier Bayesian compressive sensing } \\
\text { (CSMBCS) approach for the downlink channel } \\
\text { estimation. }\end{array}$ & $\begin{array}{l}\text { Their results shows the } \\
\text { effectiveness of the } \\
\text { approach. }\end{array}$ \\
\hline 20 & {$[45]$} & $\begin{array}{l}\text { Target Recognition } \\
\text { Based } \quad \text { Radio } \\
\text { Channel } \\
\text { Clustering } \\
\text { Algorithm }\end{array}$ & $\begin{array}{l}\text { IThey have proposed a target recognition based } \\
\text { clustering algorithm is proposed. It is used for time- } \\
\text { varying channels. Power angle spectrum (PAS) is } \\
\text { separated from estimation information by utilizing } \\
\text { Bartlett beamformer. At that point the bunches in } \\
\text { the PAS are isolated from the foundation by } \\
\text { utilizing the proposed calculation, where the } \\
\text { plentifulness appropriation of the components in the } \\
\text { PAS is considered. Besides, morphology activities } \\
\text { are connected to further partition the groups which } \\
\text { are associated with one another. The proposed } \\
\text { approach suggest the dynamic changes of the } \\
\text { clusters in real-time channel measurement. }\end{array}$ & $\begin{array}{l}\text { Their results shows the } \\
\text { effectiveness of the } \\
\text { approach. }\end{array}$ \\
\hline
\end{tabular}

Based on the study, discussion, exploration and analysis following statements have been observed:
- There is a need of efficient CHs selection as the selection of heads can affect the performance. 
- There is the need of CHs selection in a completely unbiased manner means it should be random or specific criteria.

- There is the need of prioritization in different operations, including data sink as it can be helpful in determining the thresholds.

- There is the need of efficient clustering for the data aggregation and data processing.

- There is the need for the inclusion of different parameters which can be helpful in the performance validation.

\section{Conclusion}

In this paper a systematic study and analysis have been presented based on the computational analysis of clustering techniques for the efficient cluster head selection. Several methods have been discussed and analysed and the impact has been highlighted based on the analysis. Methods have been discussed based on the method used, approach and the results. The analysis has been extended to the discussion of the pros and cons. Based on the assumptions, analysis and discussion further solutions have been suggested.

\section{Acknowledgment}

None.

\section{Conflicts of interest}

The authors have no conflicts of interest to declare.

\section{References}

[1] Iyengar SS, Brooks RR. Distributed sensor networks: sensor networking and applications (Volume Two). CRC press; 2016.

[2] Alromih A, Al-Rodhaan M, Tian Y. A randomized watermarking technique for detecting malicious data injection attacks in heterogeneous wireless sensor networks for internet of things applications. Sensors. 2018; 18(12):1-19.

[3] Bergelt R, Vodel M, Hardt W. Energy efficient handling of big data in embedded, wireless sensor networks. In sensors applications symposium 2014 (pp. 53-8). IEEE.

[4] Vodel M, Hardt W. Data aggregation in resourcelimited wireless communication environmentsdifferences between theory and praxis. In international conference on control, automation and information sciences 2012 (pp. 208-13). IEEE.

[5] Sarma HK. Grid based data gathering in multi-channel wireless sensor network. In international conference on information technology 2016 (pp. 114-7). IEEE.

[6] Muzakkari BA, Mohamed MA, Kadir MF, Mohamad Z, Jamil N. Recent advances in energy efficient-QoS aware MAC protocols for wireless sensor networks. International Journal of Advanced Computer Research. 2018; 8(38):212-28.
[7] Dubey AK. An efficient variable distance measure kmeans [VDMKM] algorithm for cluster head selection in WSN. International Journal of Innovative Technology and Exploring Engineering. 2019; 9(1): 87-92.

[8] Hammoudeh M, Newman R. Adaptive routing in wireless sensor networks: QoS optimisation for enhanced application performance. Information Fusion. 2015; 22:3-15.

[9] Khandelwal A, Jain YK. An efficient k-means algorithm for the cluster head selection based on SAW and WPM. International Journal of Advanced Computer Research. 2018; 8(37):191-202.

[10] Dubey AK, Gupta U, Jain S. Analysis of k-means clustering approach on the breast cancer Wisconsin dataset. International Journal of Computer Assisted Radiology and Surgery. 2016; 11(11):2033-47.

[11] Dubey AK, Gupta U, Jain S. Comparative study of Kmeans and fuzzy C-means algorithms on the breast cancer data. International Journal on Advanced Science, Engineering and Information Technology. 2018; 8(1):18-29.

[12] Malakooti MV, Aghasharif A, Masourzadeh N. A novel clustering algorithm for dynamic base station in wireless sensor networks based on DWT and SVD algorithms. In international conference on computing, communication and networking technologies (ICCCNT) 2015 (pp. 1-6). IEEE.

[13] Kumrawat M, Dhawan M. Optimizing energy consumption in wireless sensor network through distributed weighted clustering algorithm. In international conference on computer, communication and control (IC4) 2015 (pp. 1-5). IEEE.

[14] Desai K, Rana K. Clustering technique for wireless sensor network. In international conference on next generation computing technologies 2015 (pp. 223-7). IEEE.

[15] Bhat P, Reddy KS. Energy efficient detection of malicious nodes using secure clustering with load balance and reliable node disjoint multipath routing in wireless sensor networks. In international conference on advances in computing, communications and informatics 2015 (pp. 954-8). IEEE.

[16] Nguyen MT, Teague KA. Distributed DCT based data compression in clustered wireless sensor networks. In international conference on the design of reliable communication networks 2015 (pp. 255-8). IEEE.

[17] Zhou J, Zhang Y, Jiang Y, Chen CP, Chen L. A distributed k-means clustering algorithm in wireless sensor networks. In international conference on informative and cybernetics for computational social systems 2015 (pp. 26-30). IEEE.

[18] Tinker MS, Chinara S. Energy conservation clustering in wireless sensor networks for increased life time. In international conference on advances in computing and communication engineering 2015 (pp. 7-10). IEEE.

[19] Pant M, Dey B, Nandi S. A multihop routing protocol for wireless sensor network based on grid clustering. 
In applications and innovations in mobile computing 2015 (pp. 137-40). IEEE.

[20] Yuvaraj P, Narayana KV. EESCA: energy efficient structured clustering algorithm for wireless sensor networks. In international conference on computing, analytics and security trends 2016 (pp. 523-7). IEEE.

[21] Devi LN, Rao AN. Optimization of energy in wireless sensor networks using clustering techniques. In international conference on communication and electronics systems 2016 (pp. 1-4). IEEE.

[22] Abushiba W, Johnson P, Alharthi S, Wright C. An energy efficient and adaptive clustering for wireless sensor network (CH-leach) using leach protocol. In international computer engineering conference 2017 (pp. 50-4). IEEE.

[23] Echoukairi H, Kada A, Bouragba K, Ouzzif M. A novel centralized clustering approach based on $\mathrm{k}$ means algorithm for wireless sensor network. In computing conference (pp. 1259-62). IEEE.

[24] Masoud MZ, Jaradat Y, Zaidan D, Jannoud I. To cluster or not to cluster: a hybrid clustering protocol for WSN. In Jordan international joint conference on electrical engineering and information technology 2019 (pp. 678-82). IEEE.

[25] Liu Q, Liu M. Energy efficient cluster formation algorithm based on GA-optimized fuzzy logic for wireless sensor networks. In international conference on control and robotics engineering 2019 (pp. 16-20). IEEE.

[26] Beegum TR. Energy aware virtual backbone construction using cluster heads in wireless sensor network. In international conference on wireless communications, signal processing and networking 2017 (pp. 1656-8). IEEE.

[27] Pathak A. A bee colony inspired clustering protocol for wireless sensor networks. In international conference on computing, communication and automation 2017 (pp. 570-5). IEEE.

[28] Vançin S, Erdem E. Performance analysis of the energy efficient clustering models in wireless sensor networks. In international conference on electronics, circuits and systems 2017 (pp. 247-51). IEEE.

[29] Sofi SA, Mir RN. Natural algorithm based adaptive architecture for underwater wireless sensor networks. In international conference on wireless communications, signal processing and networking 2017 (pp. 2343-6). IEEE.

[30] Kanmani M, Kannan M, Devika S. Efficient cooperative MIMO transmission clustering algorithm for wireless sensor networks. In international conference on signal processing, communication and networking 2017 (pp. 1-6). IEEE.

[31] Huang J. Research on balanced energy consumption of wireless sensor network nodes based on clustering algorithm. In international conference on computer network, electronic and automation 2017 (pp. 300-4). IEEE.

[32] Khiani SR, Dethe CG. Design of dynamic clustering technique for enhancing life of wireless sensor network. In international conference on computing, communication, control and automation 2017 (pp. 15). IEEE.

[33] Huang J. A double cluster head based wireless sensor network routing algorithm. In international conference on software engineering and service science 2017 (pp. 846-50). IEEE.

[34] Vidhya K, Kumar KS. Channel estimation of MIMOOFDM system using PSO and GA. Arabian Journal for Science and Engineering. 2014; 39:4047-56.

[35] Irandegani $M$, Bagherizadeh $M$. Designing an asynchronous multi-channel media access control protocol based on service quality for wireless sensor networks. International Journal of Advanced Computer Research. 2017; 7(32):190-9.

[36] Fan C, Zhang YJ, Yuan X. Dynamic nested clustering for parallel PHY-layer processing in cloud-RANs. IEEE Transactions on Wireless Communications. 2015; 15(3):1881-94.

[37] Georgoulakis K, Glentis GO. Clustering based sequence equalizer in direct detection DQPSK optical signaling. In international conference on transparent optical networks 2015 (pp. 1-4). IEEE.

[38] Esswie AA, El-Absi M, Dobre OA, Ikki S, Kaiser T. A novel FDD massive MIMO system based on downlink spatial channel estimation without CSIT. In international conference on communications 2017 (pp. 1-6). IEEE.

[39] Ballal T, Al-Naffouri TY, Ahmed SF. Lowcomplexity bayesian estimation of cluster-sparse channels. IEEE Transactions on Communications. 2015; 63(11):4159-73.

[40] Cai X, Yin X, Cheng X, Yuste AP. An empirical random-cluster model for subway channels based on passive measurements in UMTS. IEEE Transactions on Communications. 2016; 64(8):3563-75.

[41] Lin X, Wu S, Jiang C, Kuang L, Yan J, Hanzo L. Estimation of broadband multiuser millimeter wave massive MIMO-OFDM channels by exploiting their sparse structure. IEEE Transactions on Wireless Communications. 2018; 17(6):3959-73.

[42] Ban Y, Xu M, Zhao Z, Li Y, Ding Z. Cluster formation with data-assisted channel estimation in cloud-radio access networks. In wireless communications and networking conference 2017 (pp. 1-6). IEEE.

[43] Zheng Q, He R, Huang C. A tracking-based multipath components clustering algorithm. In URSI Atlantic radio science meeting 2018 (pp. 1-4). IEEE.

[44] Ji W, Ren C, Qiu L. Common sparsity and cluster structure based channel estimation for downlink massive MIMO-OFDM systems. IEEE Signal Processing Letters. 2018; 26(1):59-63.

[45] Huang C, He R, Zhong Z, Ai B, Wang G, Zhong Z, et al. A novel target recognition based radio channel clustering algorithm. In international conference on wireless communications and signal processing 2018 (pp. 1-6). IEEE. 


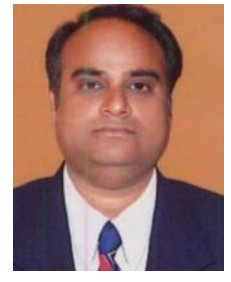

Anil Khandelwal is a Research Scholar in the department of Electronics \& Communication Engineering, Samrat Ashok Technological Institute, Vidisha, Madhya Pradesh, India. He completed his B.E. in Electronics and Telecommunication Engineering from North Maharashtra University, Jalgaon, Maharashtra in 1997 and M.Tech in Digital Communication from RGPV, Bhopal, Madhya Pradesh, India in 2010. His research interests are Wireless Sensor Network, Clustering Techniques, OFDM and MIMO.

Email: akhandelwal7@gmail.com

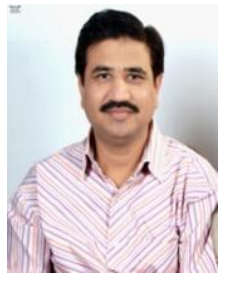

Dr. Yogendra Kumar Jain received his Ph.D. degree in Electronics \& Instrumentation Engineering from RGPV, Bhopal, Madhya Pradesh, India in 2010. He is a Professor in the Department of Electronics \& Instrumentation Engineering, Samrat Ashok Technological Institute, Vidisha, Madhya Pradesh, India since 1992. He published more than 100 research papers in various International/National Journals and Conferences. $\mathrm{He}$ is reviewer of the IEEE Transaction on Cybernetics, Man and Systems, Elsevier Journal of Information Security and Applications, INFOCOMP Journal of Computer Science and so many conferences of IEEE, Springer and also act as the member of the editorial board of reputed journals. 